\title{
Aplicação Administrativa do Direito
}

\author{
(Sintese de Hermenêutica)
}

(Continuação)

\section{Celso de Magalhães}

$$
\text { X - MÉTODO HISTÓRICO }
$$

Invenção do Direito - "As leis posteriores, desde que não sejam contrárias às leis anteriores, fazem parte delas, cujas prescrições ratificam. esclarecem ou completam". Eis aí uma conseqüência da verdade muito conhecida: o Direito não se inventa; êle é produto da evolução mais ou menos lenta do meio social.

Influência do passado - Daí decorre que, em caso de dúvida quanto ao sentido de um trecho normativo, o estudo do passado, o estudo dos trabalhos que antecederam à elaboração da norma poderá auxiliar o intérprete, esclarecendo-lhe o que se the afigurava obscuro. Essse é o método histórico de interpretação.

Superestimação - Contudo, não se deverá superestimar o valor dêsse passado, dando demasiada importância à história da norma a interpretar. O passado não representa a verdade integral, pois, se assim não fôsse, impossível seria a evolução do Direito, sempre acorde com o estado social, político e filosófico da época. O que êle contém dentro de si, vindo dêsse passado, é apenas alguma coisa que o exegeta poderá esvurmar, para melhor entender o texto, cuja aplicação the é confiada.

Materiais legislativos - Além do estudo do direito anterior, os próprios materiais legislativos servem também para a descoberta do verdadeiro alcance da norma. Esses materiais são constituídos por mensagens, exposições de motivos, memoriais, relatórios, emendas aceitas ou regeitadas, pareceres votos em separado, discursos parlamentares, tudo enfim que, na casa legislativa ou fora dela, teve alguma relação com o texto a interpretar.

Regras - Quando o exegeta pretende valer-se do método histórico para encontrar o verdadeiro sentido de um trecho de qualquer norma, deve ter presentes certas regras, cujo desconhecimento o poderá conduzir a falsas conclusões.

Identidade - Os elementos históricos a serem estudados, sejam normas anteriores, sejam materiais legislativos, devem versar assunto idêntico àquele do trecho cuja exegese se pretende fazer. E' muito fácil deixar-se o intérprete 
confundir, fazendo uso de documentos alheios, inteiramente estranhos à norma em estudo.

Sentido - Nos trabalhos legislativos, a discussão é a regra. Não há discussão parlamentar que não possa conduzir a certas confusões, donde a possibilidade de não se vislumbrar bem nitidamente o sentido final por ela atingido. Assim, só deve ser aceito o sentido que resultou dos trabalhos legislativos preparatórios, quando êsse sentido fôr evidente.

Eliminação - Um dispositivo que constava, inicialmente de um projeto e foi, depois, eliminado, nenhum efeito poderá produzir na interpretação futura da norma; mas, se quando o eliminaram, o motivo foi porque o consideraram desnecessário no texto, isso apenas significa que o legislador admitira já estar contida naquele texto, a idéia expressa no dispositivo eliminado. Assim, quando o intérprete concluir seus estudos, não poderá, de forma alguma, chegar a um resultado tal, que elimine o referido sentido: a conclusão terá de ser feita, como o seria, se o dispositivo não houvera sido eliminado.

Opiniões - Sendo o Legislativo bicameral como o é o da União, nem sempre são acordes ambas as câmaras. Se uma delas diz uma coisa e a outra diz coisa contrária, deve o intérprete desprezar ambas as opiniões, pois se elidem; mas se ambas disserem a mesma coisa, se ambas chegarem ao mesmo resultado, a êsse resultado deverá ater-se o exegeta, aproveitando a conclusão.

Discursos - Numa casa legislativa, as decisões são tomadas, seja depois de vivos debates. seja em consequiência de discursos proferidos em plenário, na hora da votação. Desde que, por fôrça de discurso não controvertido, seja aceito um princípio, vale êsse princípio mais do que se houvera resultado de intensos debates, cabendo ao intérprete dar-lhe tôda a fôrça que possui. Mas, não se prenda o intérprete a trechos isolados de discurso, por maior que seja a autoridade cultural ou política de quem o preferir: trechos esparsos não interessam à exegese.

Idéias incompatíveis - Quando há várias opiniões inconciliáveis sôbre o mesmo assunto, aceite o intérprete aquelas que se referirem sòmente a um trecho do texto, a um artigo, a um parágrafo ou alinea, excluindo tôdas as que disserem respeito à totalidade da norma a interpretar.

Títulos - O título, a epígrafe, o preâmbulo, a ementa, pôsto não façam parte do corpo da lei, também servem para sua interpretação. E' evidente que, se não estivessem de acôrdo com os princípios estabelecidos no texto a que se referem, não teriam figurado na redação final, com a aquiescência dos legisladores.

Idéias particulares - O intérprete não deverá confundir as opiniões dos parlamentares, dentro das respectivas casas legislativas, com suas idéias expressas em entrevistas públicas, ou expostas por qualquer meio de divulgação. O que foi dito pelos parlamentares, fora dos trabalhos legislativos, não interessa à exegese.

Conclusão - O método histórico é assim um precioso auxiliar da interpretação dos textos normativos, uma vez que o exegeta não se afaste das regras que o condicionam. Todavia como os demais, não pode ser o método 
histórico processo exclusivo porque, se o presente conserva alguma coisa do passado, isso não significa que tudo quanto a norma dispõe deva ser interpretado como a conservação integral do que foi outrora feito.

\section{XI - MÉTODO TELEOLÓGICO}

Objetivo - Tôda lei tende a um fim qualquer, tôda norma visa a certo objetivo. Assim, é de presumir-se que tenha o legislador disposto os elementos do texto normativo de forma a conseguir, a atingir essa finalidade, êsse objetivo. Descoberto, pois o escopo da norma, aquilo a que ela tende, será dentro dêsse critério que deverão ser interpretadas tôdas as partes do texto. E' que todos os dispositivos contidos na norma são fatôres convergentes para o mesmo fim. E' essa forma de interpretação que constitui o-método teleológico.

Meios - A identidade de fins não significa, porém, a identidade de meios. A finalidade da lei, da norma não revela, conseqüentemente, só por si, todos os meios que os legisladores quiseram pôr em prática para obter o objetivo visado, mas auxilia a compreendê-los.

Letra - A expressão verbal da norma é imutável; dessa forma, se o intérprete se apegasse exclusivamente à letra do texto, à sua expressão material, ficaria o Direito imobilizado, coisa que não se admite mais. Procurando encontrar a finalidade da norma „e buscando agir de acôrdo com essa finalidade, é que o intérprete vai adaptando o texto às várias circunstâncias ocorrentes. E' dêsse modo que o Direito se torna um todo vivo, dinâmico, capaz de evoluir, adaptando-se à evolução da sociedade.

Regras - O método teleológico, como os demais, fica subordinado a certas regras, a certos cuidados, sem o que poderá conduzir o intérprete a falsas conclusões, prejudicando a exegese.

Uniformidade - Não deve o exegeta entender as normas de modo a que produzam efeitos diferentes, quando idênticos ou semelhantes são os assuntos. A identidade ou semelhança do assunto conduz à identidade ou semelhança de objetivo; assim, entender diferentemente nos efeitos normas que tendem ao mesmo fim, é errar na interpretação.

Partes - Quando se depara ao intérprete um conjunto de normas, tôdas conduzentes ao mesmo fim, é forçoso que a exegese de cada uma, separadamente, seja feita de modo a harmonizar-se, nas conclusões, com a resultante do conjunto. E' que, nesse caso, embora distintas, agem as normas como partes integrantes de um só sistema.

Preâmbulos - O intérprete deve lembrar-se de que nos títulos e preâmbulos dos atos normativos, tanto quanto nas exposições e relatórios que os antecedem, está contida uma parte da finalidade a que visam. Antes de iniciar a interpretação do texto, pelo método teleológico, é de bom aviso examinar, pois, os títulos, as ementas, os preâmbulos.

Conclusão - O método teleológico é o que mais atende ao fim social das textos normativos. Conservando sempre o espírito da norma, mantendo sempre o objetivo a que ela visou ao ser elaborada, dar-lhe-á o intérprete a flexibilidade necessária às adaptações indispensáveis aos casos ocorrentes. 


\section{XII - EXTENSÃO DA EXEGESE}

Espírito - A letra da norma escrita não encerra todo o seu conteúdo. Desde os primórdios das instituições jurídicas se admite que nem tudo quanto está escrito prevalece como Direito e que, do mesmo modo, nem tudo quanto não está escrito deixa de constituir matéria jurídica. pois,

"Anterior e superior à palavra é a idéia de quem preceitua".

Colaboração - Ao intérprete da norma escrita cabe cooperar no sentido de que the sejam atendidos exatamente os objetivos. Isso, porém, êle não o fará, se apegar-se exclusivamente à forma do textơ, a seu elemento ma. terial, aos têrmos e vocábulos que o constituem. O alcance verdadeiro da norma está na idéia que ela encerra.

Exegese declarativa - Consiste no simples enunciado da idéia contida na norma escrita, sem the medir o alcance nem a extensão.

Exegese extensiva - Mas acontece que se impõe, por vêzes, ampliar o significado das palavras, a fôrça da expressão, procurando, por assim dizer, dilatar o conteúdo dos períodos. E' a isso que se chama - exegese entensiva ou ampla.

Exegese restrita - Outras vêzes, porém, o sentido dos têrmos deve ser restringido, deve ser limitada a significação dos períodos porque, segundo o fim colimado, a acepção própria a cada um dêles precisa ser aceita de modo particular, menos amplo e vasto, a fim de que não se conceda, nem se negue, mais do que pretendeu a norma fazer. E' a isso que se chama - exegese restrita ou restritiva.

Sentido justo - Em verdade, nem a exegese extensiva aumenta, nem a restritiva diminui o sentido do texto. O fato de dizer-se o contrário, é fôrça de expressão, sem significado jurídico. O texto, num e noutro caso, permanece o mesmo e, com êle, a idéia que a norma continha. O que se pretende, ora ampliando, ora restringindo, é manter essa idéia inalterađa. Busca-se assim, com uma e outra exegese, manter o sentido justo da norma e aplicá-la nos seus têrmos̀ exatos.

Regras - A restrição ou ampliação do conteúdo de um texto, isto é, o emprêgo da exegese extensiva ou da exegese restritiva, não deve ser feita arbitràriamente, por capricho do intérprete; há regras a fixar a escolha, e a elas deverá obediência o aplicador do Direito.

Proibição - Quando o intérprete verifica que a norma em estudo proibe fazer, ou nega alguma coisa, deverá ter presente que, nesse caso, também estão, virtualmente, proibidos ou negados todos os meios para conseguir essa mesma coisa: é o caso de exegese restrita - não conceder mais do que foi dado pela norma.

Concessão - Por outro lado, se a norma dá ou permite fazer qualquer coisa, é forçoso chegar à conclusão de que permitidos ou dados estão todos os meios necessários à obtenção dessa mesma coisa: é o caso de exegese extensiva - não permitir ou dar menos do que a norma o fêz.

Assuntos derivados - Desde que determinado assunto seja regulado por uma norma qualquer, é óbvio que seus dispositivos se aplicam, por igual, a 
tudo quanto deriva-se, necessàriamente, do referido assunto. A exegese deverá ser, então, extensiva.

Semelhança - Não raro são submetidas ao aplicador do Direito questões semelhantes a outras já anteriormente reguladas. Ora, se tais questões. podem ser comportadas dentro do mesmo conceito jurídico, a elas se estenderão, sem dúvida, os mesmos dispositivos já aplicados. A exegese deverá ser, nesse caso. extensiva.

Estado - Quando se trata da aplicação de uma norma qualquer que beneficie o Estado, a interpretação normal é a de caráter extensivo. sob condição de que, em assim fazendo, não chegue o exegeta a um resultado mais oneroso às partes.

Prazo - Tôda norma reguladora de prazo, isto é, aquelas que fixam đlata. dispõem sôbre contagem de tempo, estabelecem têrmos, são interpretadàs em sentido amplo. A exegese é extensiva.

Processos - Em se tratando de normas que facilitem a marcha dos processos, tanto os de caráter judicial, como os administrativos; de normas que estabelecem novos meios de defesa, das que concedem novos recursos, tôdas elas só admitem a exegese extensiva.

Formalidades - Normas que estabelecem formalidades; normas que dispóem sôbre regras ou condições para validade de ato jurídico ou administrativo recebem interpretação restritiva.

Contradição - Quando o intérprete encontra, numa norma, certos têrmos que são contraditados por expressões contidas no mesmo texto ou em textós semelhantes, deverá analisá-los pela exegese restritiva.

Restrição de direitos - Face a qualquer norma que restrinja direitos que limite a liberdade, que crie restrições sôbre a propriedade ou domínio, fica o. intérprete obrigado à exegese restrita.

Prescrição - Tudo quanto se relacione a normas sôbre prescrição ou decadência, sejam as que estabelecem, sejam os que suprimem os diversos prazos que disciplinam tais institutos, deve ser interpretado restritivamente.

Privilégios - Tôdas as normas que concedem privilégios e vantagens especiais devem ser interpretadas restritamente. Há contudo, uma exceção, no que se refere a anistia e indulto. A despeito de serem normas que concedem privilégio, recebem sempre interpretação extensiva, merecem exegese ampla, pois seu caráter exige que se lhes dêem a maior amplitude possível, em benefício dos interessados.

Direito singular - As normas estabelecidas de acôrda com o sistema jurídico, fundamental, e que se destinam às aplicações gerais, constituem o direito comum. Ao lado delas, outras normas podem existir, nascidas para: atender a condições particulares de ordem moral. econômica, política ou social. São regras derrogatórias do direito singular, que subtraem certos atos à sua disciplina, impondo-lhes uma disciplina nova, que constitui o- direito singular. As normas de direito singular recebem interpretação restrita.

Conclusão - O tipo da exegese a aplicar não colide com os vários métodos de interpretação; constituem, ambos, partes complementares na pesquisa da verdade contida na norma a aplicar. O método indica $\sigma$ alcance da nor- 
ma; a exegese extensiva ou restrita fixa a justa medida dêsse alcance, a fim de que, na realidade do fenômeno jurídico, nenhuma das partes interessadas sofra lesão de direito.

\section{XIII - ANALOGIA E PARIDADE}

Razão - Por vêzes ocorrem certos fatos para os quais nenhuma norma de direito existe. Não encontra, assim, quem quer que seja chamado a decidir a questão, regra alguma aplicável ao caso submetido a seu exame. Não há como recorrer, então, à exegese extensiva, pois, para tanto. mister seria a existência duma norma anterior a interpretar, e essa, no caso, não existe. Cabe. assim, buscar uma norma que discipline fato semelhante, para, ajustando-a à hipótese em exame, obter solução aceitável. E' a isso que se chama - concluir por analogia ou paridade.

Base - A conclusão por analogia ou paridade fundamenta-se no princípio de que todos os atos da mesma natureza devem ser regulados de modo semelhante. Isso não quer dizer, porém, que, para todos os casos seja aplicável a analogia ou paridade; ocasiões há em que tal processo de concluir é mesmo terminantemente proibido.

Proibições - De todos os modos oferecidos ao aplicador do Direito para solucionar os casos concretos, é a analogia ou paridade o mais perigoso, pois muito fàcilmente conduz a erros deploráveis

Penas - Assim, não se pode concluir por êsse modo, nos casos da lei penal, quando se trata de castigos, de penas mesmo fiscais, de qualquer forma em suma, de punição. Ou a penalidade está claramente regulada para o caso ocorrente, ou não existe, seja qual fôr a semelhança. Ninguém pode impor pena valendo-se da analogia ou paridade.

Ramo de direito - Os casos jurídicos são diferentemente disciplinados, conforme o ramo de Direito a que pertencem. Se o caso é, por exemplo, relativo a herança, sua disciplina pertence ao Direito Civil. Êle nada terá a ver, pois. com as regras pertinentes ao Direito Penal, Trabalhista, Processual etc... Evidentemente, se falta, para aquela questão de herança, uma regra normativa, não se poderá aplicar-1he senão uma regra de Direito Civil, cabível. Assim, as normas de Direito Penal, Trabalhista. Processual etc... não teriam cabimento, no caso, sendo, pois, inaplicável uma delas, por analogia ou paridade, para solucionar o fato. Logo, não há analogia entre ramos diferentes de Direito.

Disposições taxativas - Há textos normativos redigidos de forma altamente exclusivistas. Êles empregam expressões, cujo sentido se reduz a "só", "apenas", constituindo assim, disposições taxativas, sòmente aplicáveis ao casơ referido. Não há, pois, como tirar dêles conclusão por analogia ou paridade.

Privilégios - Todo privilégio consiste na concessão de vantagem que escapa ao direito comum, que não é geral, que constitui um favor da lei; conseqüientemente, não se poderia conceder privilégio ou vantagem, senão no caso expresso pela norma adequada. Desde que tal norma inexista, é evidente que não se poderia conceder o favor, invocando a analogia ou paridade. 
Restrições de direito - Qualquer restrição de direito importa, para alguém, num verdadeiro prejuízo. Embora não seja muito jurídica a comparação, poder-se-ia considerar uma restrição de direito como penalidade de certa natureza. Ora se ao aplicador do Direito é defeso recorrer à analogia ou paridade, nos casos de imposição de penas, ser-lhe-á da mesma forma defeso recorrer a ela para criar restrições ao direito de alguém. Ou a norma impõe, de modo inequívoco, a restrição, ou essa restrição não existirá.

Tributos - As normas relativas a impostos, taxas e emolumentos devidos ao Estado criam, para o indivíduo encargos de natureza patrimonial. São regras que oneram o patrimônio de alguém, impondo obrigações pelas quais êsse patrimônio responde. Dessa forma, tais normas não podem ser aplicadas por paridade ou analogia. Cada indivíduo só é obrigado a pagar impôsto, taxa ou emolumento, quando claramente expresso. Não importa que os casos se assemelhem; enquanto não fôr elaborada a norma que discipline um dêles, nenhuma obrigação poderá ser imposta, transplantando-se a regra de um para outro.

Vencimentos e vantagens - Os que auferem rendimentos pagos pelo Estado, isto é, aquêles que recebem vencimento, salário, gratificações ou outras quaisquer vantagens, tenham o título que tiverem, só o fazem porque uma norma anterior thes atribuiu êsse direito. Ao aplicador do Direito será, portanto, defeso valer-se da analogia ou paridade, para mandar pagar ou suprimir a êsse título, qualquer importância, seja qual fôr a pessoa e o motivo. A mesma regra se aplica a vantagens de caráter não pecuniário, assim como licenças, férias e outras.

Reǵras - Não basta que o aplicador do Direito conheça os casos em que não tem cabimento recorrer à analogia ou paridade; é preciso conhecer também os casos em que poderá e convirá recorrer a ela.

Hipótese não prevista - Ao deparar o caso concreto, o primeiro dever do aplicador do Direito consiste em examiná-lo com a devido cuidado, para enquadrá-lo dentro da norma jurídica que o discipline. Depois de tentado por todos os modos fazê-lo, sem êxito, e tendo verificado que não se trata de hipótese contida entre as questões proibitivas, ser-lhe-á facultado recorrer à analogia ou paridade. para solucioná-lo.

Correlação - Mas ainda assim, não é bastante verificar que o casa concreto constitui hipótese não prevista nas normas existentes e que poderia ser solucionado por analogia ou paridade. E' preciso, ainda, buscar, entre as normas conhecidas, uma que, por êsse processo analógico, possa ser aplicada ao caso em exame. Essa norma só poderá ser aquela na qual exista pelo menos, um ponto de identidade fundamental com a hipótese não regulada.

Princípio - Ora, a existência dum ponto de identidade fundamental pode ocorrer, mesmo quando sejam diferentes os princípios básicos contidos, um na norma a aplicar e outro, na hipótese não prevista. Mas a analogia ou paridade sòmente terá cabimento quando num e noutro caso, isto é, no que foi regulado pela norma e nơ outro, não previsto, houver identidade de próprio princípio fundamental.

Idéia - Tôda norma escrita partiu duma idéia a que procura atender; do mesmo modo, todo caso concreto, trazido a exame do aplicador do Direito. 
deve ter uma idéia por substratum. A analogia ou paridade é admissível apenas, quando a idéia que gerou a norma escrita fôr a mesma que serviu de base ao caso analisado.

Semelhança - Finalmente, o emprêgo da analogia ou paridade exige que haja indiscutível e perfeita semelhança entre a essência e os efeitos de ambos os casos, isto é, do caso já regulado pela norma existente e aquêle que, constituindo hipótese não prevista, precisa ser solucionado.

Conclusão - A analogia ou paridade não constitui método, nem processo de interpretação dos textos normativos. E' um meio do qual se vale o aplicador do Direito, para solucionar casos concretos, não ainda regulados, procurando adaptá-los a normas que, não havendo sido feitas expressamente para êles, satisfazem, todavia, à necessidade jurídica .

\section{XIV — EQÜIDADE}

Razão - A norma jurídica é, por vêzes, de rigorismo extremo, deixando de contemplar certos casos. e contemplando outros, quando são todos êles, absolutamente idênticos. E' claro que, em hipóteses dessas, a aplicação rigorosa da lei, a obediência estrita aos dispositivos da norma, redundaria em verdadeira injustiça. Daí a razão da eqüidade, que consiste em concluir de maneira a conceder ao indivíduo aquilo que, legalmente, não the deveria ser dado. pela inexistência de norma expressa.

Lacuna - Não rarơ contém as normas escritas lacunas e falhas; não raro silenciam elas a respeito de casos concretos submetidos à decisão do aplicador do Direito. E' que, por mais minucioso que fôsse o texto normativo, por maior que houvesse sido a vontade do legislador, impossível se.torna, por vêzes, descer às minúcias de todos os casos possíveis. E' para isso que serve a - equidade: corrigir, suprir as lacunas e falhas do texto escrito.

Base - A eqüidade paira acima do que a lei escreve. Não há, em verdade, fixidez na sua maneira de ser. Ela depende da cultura e da noção de Justiça contida no espírito do povo, da gente de cujo Direito se trata. A eqüidade é, pois, variável no tempo e no espaço. Ela não apresenta, assim, o modo de sentir, exclusivo, do aplicador do Direito. sua maneira de pensar; também não representa a vontade daquêle que the invocou a proteção. A eqüidade depende do sentimento dominante no seio da coletividade, onde deverá ser o caso solucionado.

Decisão - Assim, para decidir por eqüidade, não bastam os imperativos da conciência individual. Não importa aquilo que, ao aplicador do Direito, pareça justo. conforme sua maneira pessoal de entender a questão. Êle não pode criar no espírito a norma inexistente para o caso concreto, como se fôsse chamado a legislar na espécie. E' preciso estudar cuidadosamente o texto onde, ao que lhe parece, o assunto deveria estar contido; fazer o confronto dêsse texto com outros textos normativos semelhantes; compará-1o, ainda, como os princípios gerais do Direito. Mas, tudo isso êle o fará, para descobrir qual a decisão aconselhada pelas necessidades sociais, mas nunca visando apenas às necessidades do indivíduo que postula ou reclama. 
Contraindicações - A eqüidade destina-se a preencher lacunas impossíveis de evitar em textos normativos; todavia, falta-lhe autoridade para contrariar dispositivos expressos, reguladores do assunto. Quando existir um preceito claro, preciso, positivo, a eqüidade não poderá ser invocada, nem concedida contra êle. Se o preceito existe, poder-se-á alegar que é injusto, desumano, que deverá ser derrogado, extinto; não obstante, terá o aplicador do Direito de obedecer a êle, deixando para o legislador a tarefa de elaborar outra regra mais adequada às necessidades sociais. Decidir, nesse caso, por equiidade, é errar na conclusão.

Abuso - Não raro, dentrơ da Administração, se postula decisão por eqüidade, a qualquer pretexto. Ora, a eqüidade é destinada a preencher lacunas que as normas apresentam e não a substitui-las. Quando há exemplo de alguma concessão abusiva, isto é, contra-legem, não falta quem pretenda obter a mesma vantagem, alegando eqüidade. E, por vêzes, o consegue! Ora, quando a Administração contraria dispositivo de qualquer norma escrita, concedendo vantagens ou privilégios indevidos, isso não passa de um abuso, de uma irregularidade, que não pode gerar direito, nem permitir extensão: "um abuso não justifica outro".

Permissão - Śó se deve recorrer à eqüidade para atenuar o rigor de um texto, para interpretá-lo de modo mais compativel com as necessidades sociais, mas nunca para contrariar de forma expressa aquilo que o mesmo texto determina. O abuso praticado deverá ser corrigido. sem jamais permitir a prática de outro abuso, sob o manto da equiidade.

Regras - Não deve o aplicador do Direito desconhecer, além do que foi dito, certas regras às quais deverá obediência, quando the fôr impôsto o exame de um caso concreto, para decidi-lo segundo os princípios da eqüidade.

Silêncio - A primeira questão a estudar é se, realmente, a norma reguladora da espécie silencia a respeito do caso em exame. E' evidente que não silenciando a respeito, a norma oferece, de modo inequívoco, o modo de decidir. Ou concede, ou nega o pedido; logo, não haverá caso de eqüidade.

Decisão contraditória - Depois disso, formule o aplicador do Direito a decisão que gostaria de proferir, mas tenha o cuidado de examiná-la cuidadosamente, a fim de verificar se ela não contraria o espírito da norma reguladora do assunto. Não importa que o texto normativo haja silenciado; a decisão por eqüidade exige que seja mantido o espírito da norma que se vai aplicar ao caso concreto. Mas não basta que não seja contrariado o espírito da norma existente, cumpre verificar também se não se contrariam, igualmente, princípios gerais do Direito. E' que, não estando o caso concreto contido na norma reguladora, existe a possibilidade de acorde, embora com seu espírito contrariar, por outro lado, princípios gerais do Direito. Não seria, então, caso de eqüidade.

Tendências sociais - Mas o que se torna mais importante para o aplicador do Direito, quando precisa decidir por eqüidade, é o exame atento das tendências sociais, a fim de verificar se essas tendências permitem, ou mais ainda, aconselham a decisão que vai proferir. Contra o sentimento dominante no grupo social, qualquer decisão por eqüidade é contraindicada: des- 
perta o clamor público, suscita idéia de favoritismo e possibilita abusos. As decisões por eqüidade devem revestir certo caráter humanitário, sendo mesmo êsse seu cunho característico.

Penas - Não se pơde, por eqüidade, impor ou relevar penas e castigos. $\mathrm{O}$ direito punitivo é de exegese restrita, devendo ser aplicado sòmente nos casos e na forma expressso. Se certa pessoa, por exemplo, tendo cometido uma falta, deixou de ser punida, absurdo seria admitir que nunca mais pudesse o aplicador do Direito punir falta idêntica, quando the reclamassem decisão por eqüidade.

Conclusão - A eqüidade não constitui método de interpretação dos textos escritos. Dela não se vale o exegeta, mas apenas o aplicador do Di. reito, atendendo ao interêsse social, e colaborando, dessa forma, com o legislador, no disciplinamento dos casos ocorrentes.

A concessão outorgada a particulares para a execução de serviços públicos da competência da administração é, segundo a melhor doutrina dominante no direito pátrio, um contrato de direito público. Nela, por isso mesmo, prima o interêsse coletivo, dado o pressuposto de que o serviço concedido só por certas conveniências administrativas deixa de ser executado diretamente pelo Estado.

José Martins Rodrigues - Concessão de Serviços Públicos - In "Revista de Direito Administrativo" - Vol. 22, Outubro-Dezembro 1950 - Pg. 14. 